\title{
Scar endometriosis after a caesarean section: a perhaps underestimated complication
}

\author{
B. M. E. Adriaanse • R. Natté • B. W. J. Hellebrekers
}

Received: 7 April 2013 / Accepted: 15 July 2013 /Published online: 18 August 2013

(C) Springer-Verlag Berlin Heidelberg 2013

\begin{abstract}
The exact incidence of scar endometriosis is unknown. The aim of this study is to determine the incidence of endometriosis in the abdominal wall following a caesarean section. Women who underwent surgery for scar endometriosis after a caesarean section and the total number of women with caesarean sections in The Haga Teaching Hospital, a gynaecologic centre in The Netherlands, were identified by the national obstetric registration and pathology archive in the period January 1995 to December 2008. Clinical data were collected from the existing hospital records. Twenty-nine women were diagnosed with scar endometriosis after a caesarean section, and 3,047 women underwent one or more caesarean sections, resulting in an incidence of scar endometriosis of $0.95 \%$. None of the women had a history of endometriosis. Symptoms were pain $(94.0 \%)$, cyclic with menstruation $(50.0 \%)$ and swelling of the scar $(89.0 \%)$. Mean time between caesarean delivery and symptoms was 4.1 years. No recurrence occurred. This study reveals a higher incidence of endometriosis in the scar of a caesarean section than described in current literature. To improve the detection rate, more attention to medical history and physical examination is mandatory. A higher incidence warrants research into
\end{abstract}

B. M. E. Adriaanse ( $₫)$

Department of Obstetrics and Gynaecology, VU University Medical Centre, PK 6Z 170, De Boelelaan 1117,

1081 HV Amsterdam, The Netherlands

e-mail: b.adriaanse@vumc.nl

\section{R. Natté}

Department of Pathology, Haga Teaching Hospital,

The Hague, The Netherlands

B. W. J. Hellebrekers

Department of Obstetrics and Gynaecology, Haga Teaching Hospital,

The Hague, The Netherlands the pathophysiology and prevention of endometriosis in the scar of a caesarean section.

Keywords Endometriosis · Scar · Caesarean section . Surgery $\cdot$ Incidence $\cdot$ Abdominal wall

\section{Introduction}

Endometriosis is defined as functioning endometrium outside the cavum uteri and is found in $8-15 \%$ of all menstruating women [1-3]. The most common site is the ovarium and less frequent sites include peritoneum, intestine, bladder, inguinal region, lungs, pleura, pancreas, central nervous system and vertebrae $[1,2,4]$. Furthermore, endometriosis can be seen in the abdominal wall after surgery, in particular, in women with a caesarean section in history. Currently, no exact incidence rate of scar endometriosis after a caesarean section has been described and rates range from $0.03-1.73 \%$ [5-12] with an average rate of $0.50 \%$ (see Table 1 ). There are, however, only five studies $[6,8-11]$ available that calculated the incidence rate in a study group of more than 3,000 women with caesarean sections each. When we combine the total number of cases with scar endometriosis from these studies, the average incidence rate is $0.15 \%$. It is generally believed that scar endometriosis is a rare complication of a caesarean section, but the question remains whether the actual incidence is as low as been stated in most of the current literature or that the complication is underestimated.

Symptoms of endometriosis are frequently not recognised which results in delay in the diagnosis and therapy of the scar endometriosis $[13,14]$. A higher incidence justifies more attention to the diagnosis and requires research into pathophysiology and prevention. The aim of this study is to investigate the incidence of scar endometriosis after a caesarean section. 


\section{Methods}

This retrospective observational cohort study was performed in the Haga Teaching Hospital, The Hague, The Netherlands. All women with the pathological diagnosis 'endometriosis in abdominal scar' were collected by searches in the nationwide pathology registry database Pathologic Anatomic National Automated Archive (PALGA). The following terms were used for the search: endometriosis, endometriosis cyst and external endometriosis. All women who were diagnosed in the period of 1995 until 2008 were selected. The number of women who delivered by caesarean section in the Haga Teaching Hospital in the same period was determined by data of the national obstetric registration. For detailed information, records of the selected women with scar endometriosis after caesarean section were examined. The following items were recorded: surgical history, number of caesarean deliveries in history, method of caesarean delivery (Pfannenstiel/median incision), age at time of caesarean delivery, body mass index (BMI) at time of caesarean delivery, endometriosis in history (yes/no), symptoms, time between the caesarean section and symptoms of scar endometriosis, specialist who diagnosed the scar endometriosis and operated the woman, size of endometrioma and recurrence of scar endometriosis (yes/no).

\section{Results}

In the Haga Teaching Hospital, 440 women underwent surgery for (external) endometriosis from 1995 until 2008. In this group, the endometriosis was located in the abdominal wall in 34 women $(7.70 \%)$. One woman with abdominal wall endometriosis had no surgical history, in one woman, the endometriosis was located in an abdominal scar with unknown cause, and in three women, the endometriosis was located in a scar of an operation other than caesarean section (appendectomy, umbilical hernia repair and episiotomy). Twenty-nine women were diagnosed with abdominal wall endometriosis after caesarean section and underwent surgery. In total, 3,047 women underwent one or more caesarean sections from 1995 until 2008 , resulting in an incidence rate of scar endometriosis of $0.95 \%$ (95 \% CI, 0.61-1.29). Of these 29 women, 13 had their caesarean section in the Haga Teaching hospital and 16 in another hospital, leading to an incidence rate of $0.43 \%$ (95\% CI, 0.20-0.66). The results of the women with scar endometriosis after a caesarean section are shown in Table 2. The mean number of caesarean deliveries in history was 1.3 (range, 1.0-4.0), and all caesarean deliveries were performed with a Pfannenstiel incision. The mean age of the women at time of the caesarean delivery was 26.7 years (range, 19.043.0), and the mean BMI was $28.4 \mathrm{~kg} / \mathrm{m}^{2}$ (range, 16.2-52.9).
Table 1 Overview of literature concerning incidence of scar endometriosis after caesarean section

\begin{tabular}{|c|c|c|c|c|}
\hline Author & Year & $\begin{array}{l}\text { Study } \\
\text { population }\end{array}$ & $\begin{array}{l}\text { Women } \\
\text { with scar } \\
\text { endometriosis }\end{array}$ & $\begin{array}{l}\text { Reported } \\
\text { incidence }\end{array}$ \\
\hline $\begin{array}{l}\text { Nominato et al. } \\
{[10]}\end{array}$ & 2010 & 18,083 & 46 & 0.25 \\
\hline Leite et al. [8] & 2009 & 10,533 & 31 & 0.29 \\
\hline Minaglia et al. [9] & 2007 & 46,250 & 37 & 0.08 \\
\hline Singh et al. [11] & 1995 & 3,330 & 6 & 0.18 \\
\hline Bottino et al. [5] & 1990 & 200 & 2 & 1.00 \\
\hline Wolf et al. [12] & 1989 & 289 & 5 & 1.73 \\
\hline Chatterjee [6] & 1980 & 3,736 & 1 & 0.03 \\
\hline Field et al. [7] & 1962 & 425 & 2 & 0.47 \\
\hline
\end{tabular}

None of the women had a history of previously diagnosed endometriosis. Symptoms were pain $(94.0 \%), 50.0 \%$ cyclic with menstruation and swelling of the scar $(89.0 \%)$. Mean time between caesarean delivery and symptoms was 4.1 year (range, 0.0-7.0). The endometriosis was diagnosed in 18 women $(62.1 \%)$ by a gynaecologist and in 11 women $(37.9 \%)$ by a general surgeon. The resection of the endometriosis was performed 20 times $(69.0 \%)$ by a gynaecologist and 9 times $(31.0 \%)$ by a general surgeon. The mean size of the excised endometriomas was $2.7 \mathrm{~cm}$ (range, 1.0-5.0). No recurrences were diagnosed.

\section{Discussion}

Abdominal wall endometriosis is considered to be a rare complication of a caesarean section. This study describes a large series of women with scar endometriosis and reveals a higher incidence than published in current literature. Rates of

Table 2 Characteristics of women with abdominal wall endometriosis after caesarean section

\begin{tabular}{lll}
\hline & Mean & Range \\
Age (years) & 26.7 & $19.0-43.0$ \\
BMI $\left(\mathrm{kg} / \mathrm{m}^{2}\right)$ & 28.4 & $16.2-52.9$ \\
Interval CS—-symptoms (years) & 4.1 & $0.0-7.0$ \\
Size endometrioma (cm) & 2.7 & $1.0-5.0$ \\
CS in history (number) & 1.3 & $1.0-4.0$ \\
& Pain & Swelling scar \\
Symptoms & $94.0 \%$ & $89.0 \%$ \\
& Gynaecologist & General surgeon \\
Diagnosed by & $62.1 \%$ & $37.9 \%$ \\
Operated by & $69.0 \%$ & $31.0 \%$ \\
\hline
\end{tabular}

$\mathrm{Kg}$ kilogramme, $\mathrm{m}^{2}$ metres square, $C S$ caesarean section, $\mathrm{cm}$ centimetre 
scar endometriosis after a caesarean section range from 0.03$1.73 \%$ [5-12] with an average rate of $0.50 \%$ (see Table 2). There are, however, only five studies $[6,8-11]$ available that calculated the incidence rate in a study group of more than 3,000 women each. When we combine the total number of cases with scar endometriosis from these studies, the average incidence rate is $0.15 \%$. Many articles refer to studies from
1956-1995 [6, 7, 11, 15], see Table 1 . They report an incidence rate of $0.03-0.47 \%$ and refer to a study of Chatterjee [6] who described 17 cases in 1980 with an incidence of $0.03 \%$ and Field et al. [7] who reported $0.47 \%$ in 1962 based on only two women with scar endometriosis after a caesarean section. In the current study, we included 29 women with scar endometriosis after a caesarean section with an incidence rate

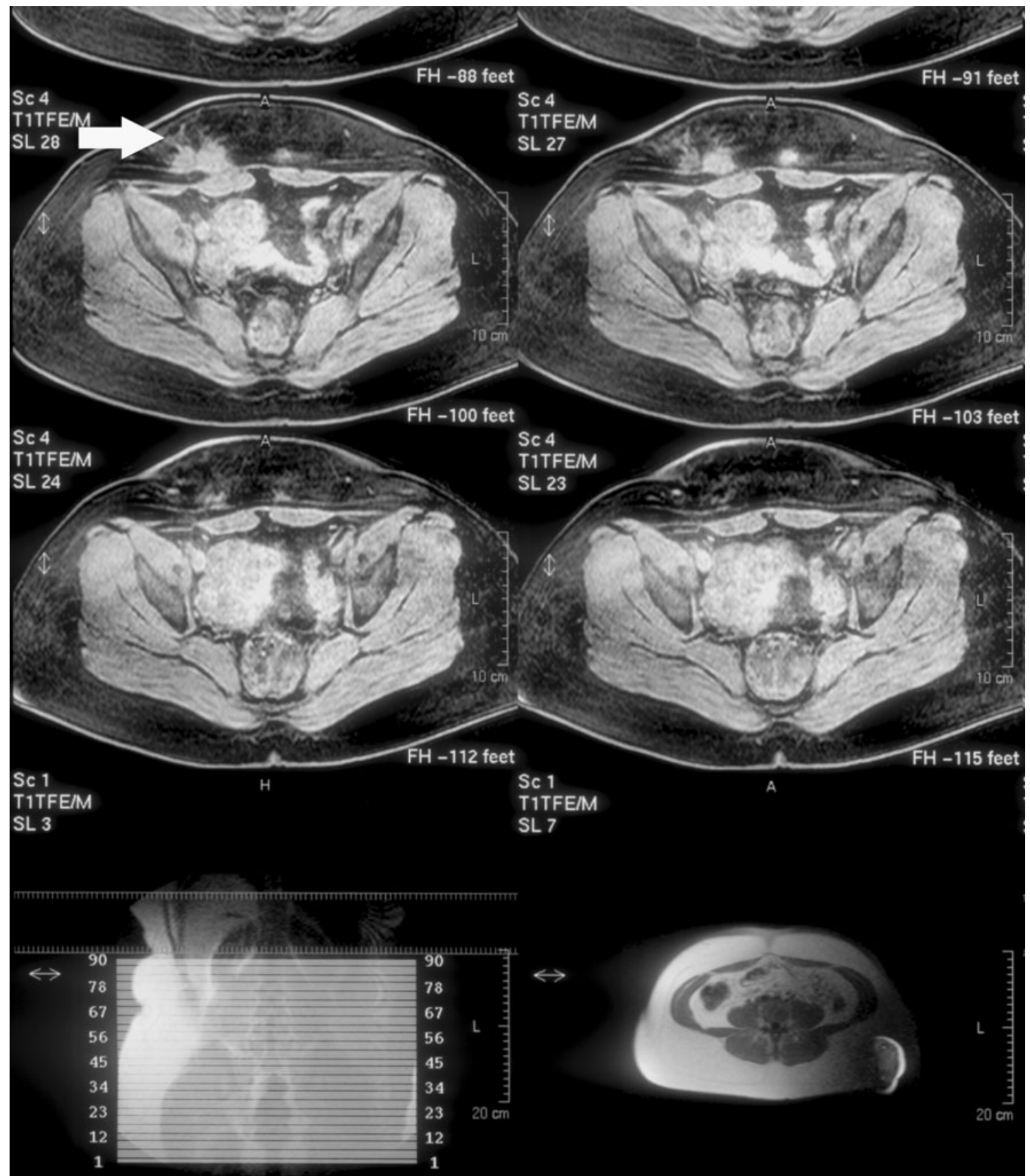

AP 10 post

Fig. 1 MRI of a patient with scar endometriosis. Endometriosis depositions in the right part of the Pfannenstiel scar in the abdominal wall 
of $0.95 \%$ (95\% CI, 0.61-1.29). Importantly, our incidence rate is based on the pathological diagnosis. Women with endometriosis who did not undergo surgery are not included. This points to an even higher incidence rate of scar endometriosis after a caesarean delivery. A few other studies with more than 30 women with scar endometriosis after a caesarean section have been published. A large study of Minaglia et al. [9] reported an incidence of $0.08 \%$ with 37 women with scar endometriosis from 1975 to 2005 , and Leite et al. [8] calculated an incidence of $0.29 \%$ with 31 women with scar endometriosis. Another large case series has been published by Bektas et al. [16] who studied retrospectively 36 cases of scar endometriosis after caesarean section. However, no incidence has been described in their study. Nominato et al. [10] described in a retrospective observational cohort study of 46 cases a lower incidence $(0.25 \%)$. Our study, however, covers a more recent study period (1995-2008) than the study of Nominato et al. (1978-2003) and Minaglia et al. (19752005). The higher incidence in our study might be explained by more awareness of scar endometriosis in the last decade and more accessible imaging possibilities. Also, the fact that 9 out of 29 women $(31.0 \%)$ were diagnosed and operated upon by a general surgeon might indicate that much of the burden of scar endometriosis happens not within the view of the gynaecologist. Although the incidence is still below $1.0 \%$, the incidence is higher than expected based on current literature, and, with this study, we want to emphasize that endometriosis should not be regarded as a rare complication of a caesarean section. Furthermore, a higher incidence requires more attention to this complication, in particular with increasing rates of caesarean sections [17-19].

Unfortunately, the pathophysiology is still not clear. Scar endometriosis after caesarean section is most likely caused by iatrogenic dissemination of decidual tissue. However, this will not explain the existence of endometriosis in the abdominal wall without any previous surgery. Different pathophysiological theories for abdominal wall endometriosis have been described. Sampson's theory postulated the implantation or retrograde menstruation hypothesis which states that endometrial tissue from the uterus is shed during menstruation and transported retrograde through the fallopian tubes, thereby gaining access to and implanting on pelvic structures [20-24]. Another theory suggests lymphatic or vascular dissemination, and a third explanation states that cells in the abdomen undergo metaplasia induced by hormonal manipulation [22]. Still, in our opinion, most of the cases can be explained by iatrogenic dissemination of decidual tissue.

The diagnosis of scar endometriosis can be difficult. In our study, women presented to the clinic with symptoms months to years after the caesarean section, as reported earlier in other studies $[8,10,16]$. Frequently, they presented with vague symptoms such as abdominal pain. The diagnosis of scar endometriosis should be based on symptoms of pain that

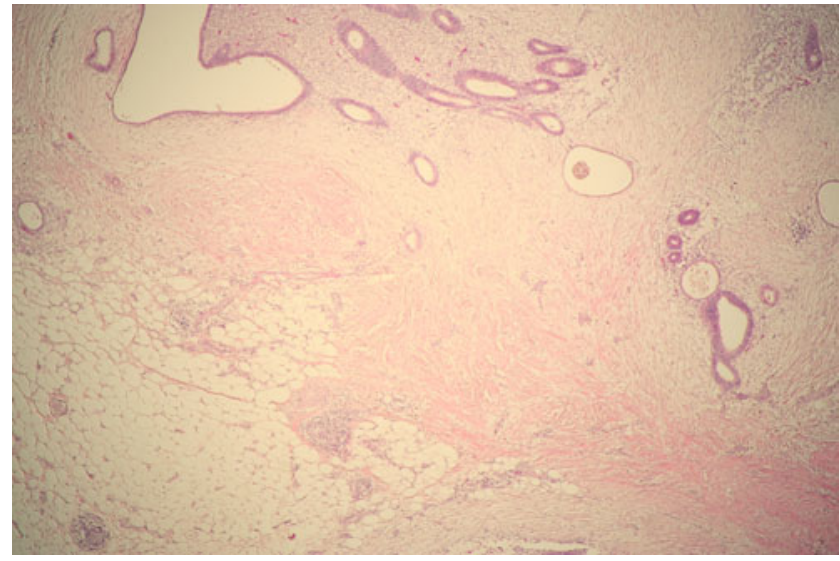

Fig. 2 Histology of scar endometriosis. Microscopy 40×. Disorderly arranged endometrial glands within densely collagenized stroma and fatty tissue. There is little endometrial stroma around the glands in the upper part of the figure

coincides with the menstrual period or tumours in the scar after abdominal surgery [8]. This awareness applies to gynaecologists as well as to other specialists who are faced with these women, like general practitioners and surgeons. Other abnormalities should be excluded and differential diagnosis includes lipoma, haematoma, umbilical hernia, soft tissue sarcoma, abscess, carcinoma (primary), metastasis and corpus alienum. Diagnosis can be made by ultrasonography or MRI (not specific), see Fig. 1, and needle biopsy (specific) [25]. In particular, ultrasonography is a useful tool to detect scar endometriosis in an early stage [26, 27]. However, ultrasound accuracy is reduced in obese patients. Early diagnosis is of importance since delayed diagnosis creates repair problems during surgery, the possible need of meshes and can cause deformities. Histological diagnosis of endometriosis is based on the identification of characteristic endometrial glands and associated stromal cells outside the cavum uteri [28], as illustrated in Figs. 2 and 3. Therapy with oral anticonceptives, progestagens and androgens give reduction

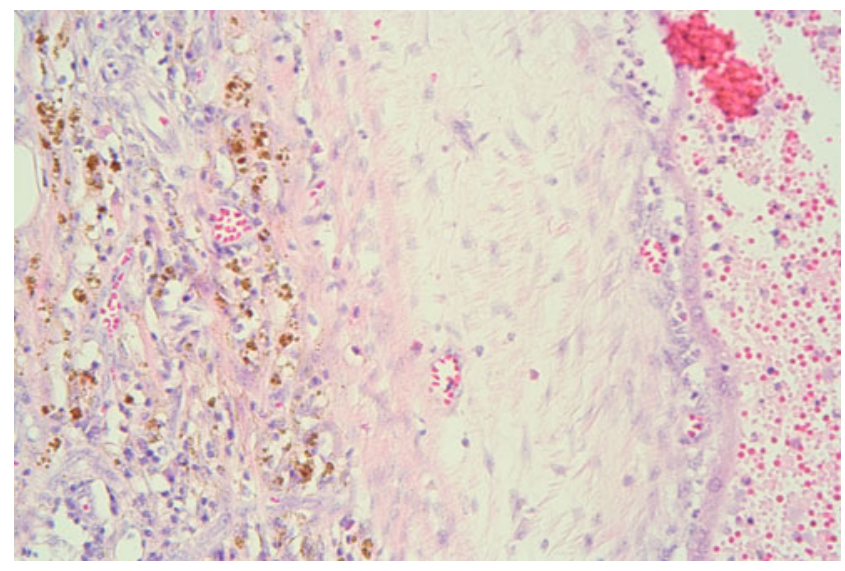

Fig. 3 Histology of scar endometriosis. Microscopy $400 \times$. Characteristic iron deposition below endometrium epithelium as a sign of old haemorrhage 
of the symptoms temporarily, with recurrence after discontinuation of the therapy. A wide surgical excision is usually curative $[11,16]$. In none of the women in this study a recurrence occurred.

Removing decidual tissue from the wound before closing and cleansing with $\mathrm{NaCl}$ (normal saline solution) has been described as a preventive measure [29]. Intraoperative contamination of the surrounding tissue with the endometrial cells is a situation that should be taken into account during operations in the pelvis. Therefore, sweeping the uterus with a gauze during a caesarean delivery should be limited since it could be an important factor in the pathogenesis of scar endometriosis [16]. Further research is necessary to determine the exact role of this factor. In addition, preventive measures could have consequences for other types of surgery as oncologic surgery, where the mechanism of cancer recurrence in a scar, shows many similarities with scar endometriosis [30]. Given the magnitude of caesarean sections performed, studies on preventive measures could thus have importance for other fields of surgery.

A limitation of this study is the restriction of research to only one hospital in the Netherlands. Therefore, not all women with scar endometriosis had their caesarean section in the Haga Teaching Hospital. We assumed, however, that this number of women is comparable to the number of women who had their caesarean section in the Haga Teaching Hospital and surgery for scar endometriosis in another hospital. Moreover, this methodology was also used in the studies referred to in Table 2. This is the one of the first studies which described a higher incidence than has been established previously. Additional research by other groups is needed to confirm our data and conclusions. Furthermore, our study only describes the incidence of women who underwent surgery, not the women with scar endometriosis who did not undergo surgery. Therefore, the incidence is even higher than described in the present study.

In conclusion, this study reveals a higher incidence of endometriosis in the scar of a caesarean section than described in current literature. To improve the detection rate of scar endometriosis, more attention to medical history and physical examination is mandatory. The higher incidence warrants research into the pathophysiology and prevention of abdominal wall endometriosis after a caesarean section.

Conflict of interest No disclosure of interest.

\section{References}

1. Albrecht LE, Tron V, Rivers JK (1995) Cutaneous endometriosis. Int J Dermatol 34:261-262

2. Bergqvist A (1992) Extragenital endometriosis. A review. Eur J Surg 158:7-12
3. Patterson GK, Winburn GB (1999) Abdominal wall endometriomas: report of eight cases. Am Surg 65:36-39

4. DeSanto DA, McBirnie JE (1949) Endometriosis: a clinical and pathological study of 219 cases. Calif Med 71:274-279

5. Bottino G, Marinello M, Menna C, Torchio B, Vergano R (1990) Endometriosis of the lower abdominal wall. Report of two cases secondary to cesarean section. Minerva Ginecol 42:283-285

6. Chatterjee SK (1980) Scar endometriosis: a clinicopathologic study of 17 cases. Obstet Gynecol 56:81-84

7. Field CA, Banner EA, Symmonds RE (1962) Endometriosis of abdominal scar after cesarean section. Proc Staff Meet Mayo Clin $37: 12-15$

8. Leite GK, Carvalho LF, Korkes H, Guazzelli TF, Kenj G, Viana AT (2009) Scar endometrioma following obstetric surgical incisions: retrospective study on 33 cases and review of the literature. São Paulo Med J 127:270-277

9. Minaglia S, Mishell DR Jr, Ballard CA (2007) Incisional endometriomas after cesarean section: a case series. J Reprod Med $52: 630-634$

10. Nominato NS, Prates LF, Lauar I, Morais J, Maia L, Geber S (2010) Caesarean section greatly increases risk of scar endometriosis. Eur J Obstet Gynecol Reprod Biol 152:83-85

11. Singh KK, Lessells AM, Adam DJ, Jordan C, Miles WF, Macintyre IM, Greig JD (1995) Presentation of endometriosis to general surgeons: a 10-year experience. Br J Surg 82:1349-1351

12. Wolf GC, Singh KB (1989) Cesarean scar endometriosis: a review. Obstet Gynecol Surv 44:89-95

13. Nirula R, Greaney GC (2000) Incisional endometriosis: an underappreciated diagnosis in general surgery. J Am Coll Surg 190:404-407

14. Wolf Y, Haddad R, Werbin N, Skornick Y, Kaplan O (1996) Endometriosis in abdominal scars: a diagnostic pitfall. Am Surg 62:10421044

15. Nora E Sr, Meyer KA, Carbonera P (1956) Ectopic endometrium in abdominal scars following cesarean section. Am J Obstet Gynecol $71: 876-884$

16. Bektas H, Bilsel Y, Sari YS, Ersoz F, Koc O, Deniz M, Boran B, Huq GE (2010) Abdominal wall endometrioma: a 10-year experience and brief review of the literature. J Surg Res 164:e77e81

17. Blanchette H (2011) The rising cesarean delivery rate in America: what are the consequences? Obstet Gynecol 118: $687-690$

18. O’Dwyer V, Hogan JL, Farah N, Kennelly MM, Fitzpatrick C, Turner MJ (2012) Maternal mortality and the rising cesarean rate. Int J Gynaecol Obstet 116:162-164

19. Wax JR, Cartin A, Pinette MG, Blackstone J (2004) Patient choice cesarean: an evidence-based review. Obstet Gynecol Surv 59:601-616

20. Sampson J (1927) Peritoneal endometriosis due to menstrual dissemination of endometrial tissue into the peritoneal cavity. Am J Obstet Gynecol 14:422-469

21. De Ziegler D, Borghese B, Chapron C (2010) Endometriosis and infertility: pathophysiology and management. Lancet 376:730-738

22. Horton JD, Dezee KJ, Ahnfeldt EP, Wagner M (2008) Abdominal wall endometriosis: a surgeon's perspective and review of 445 cases. Am J Surg 196:207-212

23. Gabriel A, Shores JT, Poblete M, Victorio A, Gupta S (2007) Abdominal wall endometrioma: case report and review. Ann Plast Surg 58:691-693

24. Seli E, Berkkanoglu M, Arici A (2003) Pathogenesis of endometriosis. Obstet Gynecol Clin N Am 30:41-61

25. Medeiros FC, Cavalcante DI, Medeiros MA, Eleuterio J Jr (2011) Fine-needle aspiration cytology of scar endometriosis: study of seven cases and literature review. Diagn Cytopathol $39: 18-21$ 
26. Francica G (2012) Reliable clinical and sonographic findings in the diagnosis of abdominal wall endometriosis near cesarean section scar. World J Radiol 4:135-140

27. Hensen JH, Van Breda Vriesman AC, Puylaert JB (2006) Abdominal wall endometriosis: clinical presentation and imaging features with emphasis on sonography. AJR Am J Roentgenol 186:616-620

28. Pathan SK, Kapila K, Haji BE, Mallik MK, Al-Ansary TA, George SS, Das DK, Francis IM (2005) Cytomorphological spectrum in scar endometriosis: a study of eight cases. Cytopathology 16:94-99

29. Wasfie T, Gomez E, Seon S, Zado B (2002) Abdominal wall endometrioma after cesarean section: a preventable complication. Int Surg 87:175-177

30. Reilly WT, Nelson H, Schroeder G, Wieand HS, Bolton J, O'Connell MJ (1996) Wound recurrence following conventional treatment of colorectal cancer. A rare but perhaps underestimated problem. Dis Colon Rectum 39:200-207 